\title{
The effect of microbial calcite precipitation on the retention properties of unsaturated fine-grained soils: discussion of the governing factors
}

\author{
R. Saffari ${ }^{1}, E$. Nikooee ${ }^{1,}{ }^{*}$, and $G$. Habibagahi ${ }^{1}$ \\ ${ }^{1}$ Shiraz University, Department of Civil and Environmental Engineering, Shiraz, Iran
}

\begin{abstract}
In recent years, biogeotechnology has been introduced as a novel and environmentally friendly technique for soil improvement. The need to address global warming and the adverse environmental effects of the chemical additives have led to the emergence and development of the techniques which use calcite producing microorganisms in order to improve soil mechanical properties. While the effects of microbial induced calcite precipitation (MICP) on the hydraulics and mechanics of saturated coarse-grained soils have been well examined and studied, there is not yet much information on the effects these microorganisms would have on the unsaturated soil mechanical behaviour. The first step, in this regard, is to understand the effect of the processes involved in the MICP on the soil retention properties. Soil water suction is a key factor controlling soil hydraulic and mechanical behaviour. In this study, the influence of MICP on the soil total suction in an unsaturated fine-grained soil sample has been explored using filter paper experiment. The results of this study revealed that by increasing the amount of bacterial solution, the soil saturation-total suction curves are significantly affected. The soil water retention changes are attributed to the change in double layer thickness as well as the precipitation of calcite crystals.
\end{abstract}

\section{Introduction}

In recent years, the urgent need to address the global warming has led to the emergence of new scientific solutions and approaches to the conventional engineering problems. One such approach has been searching for alternative soil improvement techniques. Soil improvement by means of microorganisms has proved to be effective in terms of enhancing soil mechanical and hydraulic properties and durability against sever environmental conditions [1-3].

The biological soil improvement has been employed for various engineering purposes such as increasing shear strength [4,5], mitigating the liquefaction potential [6-8], and reducing the swelling and collapse potential in fine-grained problematic soils $[9,10]$.

As two third of the earth surface is covered by arid and semiarid regions, one would expect the climatic changes would bring about short intense rainfall periods in such regions in which the soil layers will experience not only saturated state but also unsaturated conditions. In such regions knowledge of unsaturated soil behavior would be essential to understand the changes that in the soil hydromechanical behavior would occur as a result of the change in the soil degree of saturation.

The effects of biological soil improvement on the saturated soil hydromechanical behavior have been studied well in-depth in the last couple of years. However, in order to implement various types of biological soil improvement such as microbial induced calcite precipitation in the field and in engineering projects, one would need to understand their influence on the unsaturated soil hydraulic and mechanical properties. One such property is the soil water retention curve. The soil suction is a key factor governing unsaturated soil mechanical and hydraulic behavior. In this study, in order to address the effects of microbial calcite precipitation on the soil total suction, filter paper technique has been employed and the variation in retention properties of a fine-grained soil sample under different treatment scenarios such as different bacterial solution densities and the ratio of bacterial solution to dry soil weight has been looked into. Finally, governing mechanisms and processes which alter the soil retention properties have been discussed.

\section{Materials and method}

\subsection{Sample preparation and experimental procedure}

The fine-grained soil sample whose retention properties were studied after treatment by the calcite precipitating bacteria was a swelling soil sample, a mixture of Silty Sand, Kaolinite, and Bentonite with the weight percentages of $70 \%, 15 \%$, and $15 \%$, respectively. 
In order to use MICP for improving soil samples, the Bacillus Sphaericus Bacteria is utilized. Lyophilized ampules of Bacillus Sphaericus Bacteria under strain name of PTCC 1487 were obtained from Iranian Organization of Scientific Research (IROST). Table 1 presents the ingredients of the culture media used to cultivate Bacillus Sphaericus. The ingredients of culture media excluding Urea were, first, poured into distilled water and the resulting solution was autoclaved for 20 minutes at $120 \mathrm{C}$. Urea was then added by means of a filter paper (with opening size of 0.22 micrometer).

The optical density of the bacterial solution was measured as an indicator of the bacterial concentration. For this purpose, a photo-spectrometer was employed. Figure 1 depicts the growth rate curve of the bacteria.

Table 1. Culture media composition

\begin{tabular}{|l|c|}
\hline Components of liquid culture media & Amount (g/L) \\
\hline Sodium bicarbonate & 2.12 \\
\hline Nutrient broth & 3 \\
\hline Ammonium chloride & 10 \\
\hline Yeast extract & 20 \\
\hline Urea & 10 \\
\hline
\end{tabular}

The soil samples were prepared with $12 \%, 14 \%$, $16 \%, 18 \%, 20 \%, 22 \%$, and $24 \%$ moisture contents. For about five minutes, the treatment solution was blended with soil to assure the uniform distribution through the sample before compaction. Then the mixtures were placed in closed and air-tight containers which were able to keep the moisture for 24 hours. The selection of a 24hour curing time was based on the previous studies addressing the effect of curing time on the performance of MICP in mitigating the soil swelling potential [9]. Furthermore, mixing soil with the solution rather than injecting the solution is more practically plausible for fine-grained soils. After 24 hours, the samples were statically compacted at the compaction rate of $2 \mathrm{~mm}$ per minute.

The compacted and treated samples were then kept in zipped plastic containers for 4 days. After 4 days, the filter papers were placed on the samples. Following ASTM D5298, one ring was located over the compacted sample, and 2 filters over the ring to measure the total suction (Figure 2). After 10 days, the weights of filters were measured using a balance with $0.0001 \mathrm{~g}$ precision in order to obtain their moisture contents. The total suction was measured by means of the moisture content of filters over the ring whose moisture content was obtained and averaged. The calibration graph of ASTM D5298 (Figure 3) was then employed to find the total suction value corresponding to each moisture content.

The effects of various bacterial concentrations $(\mathrm{OD}=0,1.7,2,2.3)$ on the retention properties of samples were studied. In order to prepare the treatment solution, a ratio of bacterial solution to calcium chloride of one was adopted. Next, the soil was treated with the prepared solution using different amounts (i.e., $12 \%$ and $14 \%$. of soil dry weight). The selected range of design factors, namely, treatment solution to dry soil weight ratios and the bacterial solution optical density were considered the same as the range which is used in practical applications (such as swelling soil improvement) [9].

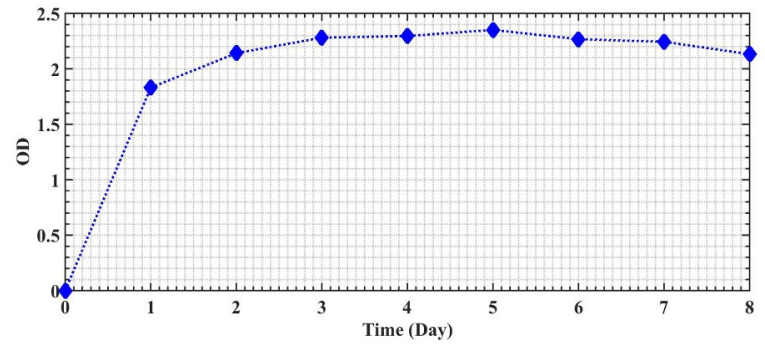

Fig. 1. Growth rate diagram for the bacillus sphaericus used in this study (OD in vertical axis stands for optical density).



Fig. 2. Placement of the filter papers.



Fig. 3. Calibration curve of Whatman filter paper 42 (ASTM D5298).

\section{Results and discussion}

In Figures 4 and 5, the soil water retention curves (SWRCs) of the samples treated with biological treatment solution of $12 \%$ (6\% bacteria and $6 \%$ calcium chloride) and those treated with biological treatment solution of $14 \%$ (7\% bacterial solution and 7\% calcium chloride) are presented, respectively. In these figures, the variation of gravimetric water content versus total suction is illustrated.

As can be seen, by increasing the bacterial density, the retention curves first move to the right, and up, next, surpassing a certain bacterial density results in their moving back and downward. In other words, an increase 
in the suction which is required to drain the soil occurs initially by increasing the bacterial density, afterwards a decrease in the suction corresponding to the the same saturation is observed.

The observed patterns can be attributed to the effects of different mechanisms and the biogeochemical reactions involved in the MICP on the soil fabric and consequently on the soil retention properties.



Fig. 4. Variation of water content with total suction for finegrained sample mixed with the treatment solution $12 \%$.



Fig. 5. Variation of water content with total suction for finegrained sample mixed with the treatment solution $14 \%(\mathrm{OD}=0$ means untreated sample).

At first and at bacterial concentrations (ODs) less than 1.7, increasing the bacterial concentration results to the decrease in the pore radii, and subsequently, the increase in the suction required for the soil drainage. This can be attributed to the processes such as biocementation and bio-clogging. However, there are other processes whose effects on the retention properties can be competing with the effects of bio-clogging and biocementation.

Saffari et al. (2019) have postulated that by further increase in the bacterial concentration, the effect of the processes which influence the double layer thickness becomes more pronounced as compared to the bioclogging and biocementation, thereby, the retention curves move back and downward [11].

Saffari et al. (2019) observed the same patterns in the water content-matric suction curves (i.e., the initial increase in the air entry values, and then its decrease with the increase in the bacterial cell concentration) [11]. The current study revealed the same pattern in the water content-total suction curves.

As the cell concentration augments, the ammonium and calcite production rate are changed. Stocks-Fischer et al. (1999) stated that at the higher cell numbers of Bacillus pasteurii, the ammonium production rate is significantly decreased (i.e., at the higher cell concertation, the final $\mathrm{pH}$ would be less than that at a lower cell concentration) [12]. One would note that a lower $\mathrm{pH}$ level would result in the lower thickness of the double diffuse layer [13-15].

Although, the results of Stocks-Fischer et al (1999) describe the metabolism of Bacillus pasteurii, and not the Bacillus Sphaericus used in this study, it can at least give primary clues on the possible mechanisms responsible for the patterns observed in the change of the retention curves by increasing the bacterial cell concentration [12].

Last but not the least, according to the observations of Saffari et al. (2015), contrary to the fine-grained soils, the increase in the bacterial concentration results in the monotonic increase in the air entry value in coarsegrained soils (i.e., due to the dominant influence of bioclogging on the retention properties and the absence of double layer effects) [16].

\section{Concluding remarks and future research directions}

In this study, the effects of biological treatment by Bacillus Sphaericus on the water content-total suction relationships of a fine-grained soil (low plasticity clay) were investigated. By increasing bacterial concentration, the value of total suction required to drain the soil at a certain saturation was first increased and then decreased. It was speculated that two mechanisms govern the observed behaviour in fine grained soils. At first, by increasing the bacterial concentration, bio-cementation brings about the clogging of pores of smaller radii, thereby, causing the increase in the matric suction required to drain the soil. Surpassing a certain bacterial density, the effect of bacteria and ions released during the bio-geo-chemical processes takes the lead in the competition of the processes, thereby, resulting in a decrease of double layer thickness and hence, a reduction in the matric suction. Given the complexity of the interactions in the clay-water-bacteria system, further research is required to not only confirm the patterns observed but also further elucidate the mechanisms behind the observations.

\section{References}

1. L. Cheng, M. A. Shahin, and D. Mujah, J. Geotech. Geoenviron., 143, 1 (2016).

2. E. Salifu, E. MacLachlan, K. R. Iyer, C. W. Knapp, and A. Tarantino, Eng. Geol., 201, 96-105. (2016).

3. P. Ghasemi, A. Zamani, and B. Montoya, In Eighth International Conference on Case Histories in Geotechnical Engineering (Geo-Congress 2019) American Society of Civil Engineers. (2019).

4. R. Saffari, G. Habibagahi, E. Nikooee, and A. Niazi, IJST-T CIV. ENG., 41, 4, 405-414 (2017).

5. L. Cheng, and M. A. Shahin, In Ecological Wisdom Inspired Restoration Engineering (47-68) Springer, Singapore. (2019).

6. B. Montoya, J. DeJong, R. Boulanger, D. Wilson, R. Gerhard, A. Ganchenko, J. and Chou, GeoCongress 
2012, 1918-1927. doi: 10.1061/9780784412121.197 (2012)

7. B. M. Montoya, J. T. DeJong, and R. W. Boulanger, Géotechnique, 63, 4, 302-312 (2013).

8. E. Jr. Kavazanjian, and S. O'Donnell, IFCEE 2015: 2286-2295. doi: 10.1061/9780784479087.212 (2015)

9. M. Sadjadi, E. Nikooee, and G. Habibagahi. In: Unsaturated Soils: Research and Applications, 917922. (2014)

10. B. N. Sisakht, E. Nikooee, G. Habibagahi, A. Niazi. Proc. European Conf. Soil Mechanics and Foundation Eng. (ECSMGE), Edinburgh (2015).

11. R. Saffari, E. Nikooee, G. Habibagahi, and M. T. van Genuchten, J. Geotech. Geoenviron., 145, 7 (2019)

12. S. Stocks-Fischer, J. K. Galinat, and S. S. Bang, Soil Biol. Biochem., 31, 11, 1563-1571 (1999).

13. J. Mitchell, Fundamentals of Soil Behavior, (John Wiley \& Sons, New York, 1993).

14. H. Van Olphen, An Introduction to Clay Colloid Chemistry, (Krieger Publishing Company, 1991).

15. I. Gratchev, and I. Towhata, Soils and Foundations, 53, 3, 469-476 (2013).

16. R. Saffari, G. Habibagahi, E. Nikooee, and A. Niazi, In Unsaturated Soil Mechanics-from Theory to Practice: Proceedings of the 6th Asia Pacific Conference on Unsaturated Soils (Guilin, China, 2326 October 2015) (445). CRC Press (2015) 